\title{
On the origin of sperm epigenetic heterogeneity
}

\author{
Sandra Laurentino, Jennifer Borgmann and Jörg Gromoll \\ Centre of Reproductive Medicine and Andrology, Albert-Schweitzer Campus, Münster, Germany \\ Correspondence should be addressed to J Gromoll; Email: joerg.gromol/@ukmuenster.de
}

\begin{abstract}
The influence of epigenetic modifications on reproduction and on the function of male germ cells has been thoroughly demonstrated. In particular, aberrant DNA methylation levels in sperm have been associated with abnormal sperm parameters, lower fertilization rates and impaired embryo development. Recent reports have indicated that human sperm might be epigenetically heterogeneous and that abnormal DNA methylation levels found in the sperm of infertile men could be due to the presence of sperm populations with different epigenetic quality. However, the origin and the contribution of different germ cell types to this suspected heterogeneity remain unclear. In this review, we focus on sperm epigenetics at the DNA methylation level and its importance in reproduction. We take into account the latest developments and hypotheses concerning the functional significance of epigenetic heterogeneity coming from the field of stem cell and cancer biology and discuss the potential importance and consequences of sperm epigenetic heterogeneity for reproduction, male (in)fertility and assisted reproductive technologies (ART). Based on the current information, we propose a model in which spermatogonial stem cell variability, either intrinsic or due to external factors (such as endocrine action and environmental stimuli), can lead to epigenetic sperm heterogeneity, sperm epimutations and male infertility. The elucidation of the precise causes for epimutations, the conception of adequate therapeutic options and the development of sperm selection technologies based on epigenetic quality should be regarded as crucial to the improvement of ART outcome in the near future. Reproduction (2016) 151 R71-R78
\end{abstract}

\section{Introduction}

Infertility is a multifactorial disease that can be attributed in about half of the cases to the male partner (Tüttelmann et al. 2008). However, a large proportion of men is diagnosed with idiopathic infertility due to the lack of any known causative factor (Tüttelmann et al. 2008). Epigenetic modifications (e.g. modification of histones, non-coding RNAs and DNA methylation) relate to changes in the DNA that do not affect the nucleotide sequence (Berger et al. 2009) and have been suggested to be involved in the aetiology of male idiopathic infertility (Carrell 2012). In particular, the association between aberrant methylation in sperm DNA and male idiopathic infertility and adverse reproductive outcome has been well established in the literature (see Supplementary Table 1, see section on supplementary data given at the end of this article). This relationship has been further emphasized by a meta-analysis that found high odds ratios (OR) associating the aberrant methylation of two imprinted genes in the sperm of men with male infertility (Kläver \& Gromoll 2014). However, epimutations in sperm and the possible underlying heterogeneity have not been studied mostly due to technology-based limitations. Only recently, new technologies enabled the study of DNA methylation in single sperm, spermatogonia and gonocytes to address potential epigenetic heterogeneity among and within these cell types (Jenkins et al. 2014, Kuhtz et al. 2014, Laurentino et al. 2015).
The purpose of this review is to discuss the influence of epigenetics, particularly DNA methylation, on male infertility in the light of the new concept of epigenetic heterogeneity and its relevance to reproduction.

\section{DNA methylation and imprinting}

The epigenetic modification most frequently evaluated in the context of idiopathic male infertility is DNA methylation, which refers to the methylation of cytosines at CpG (cytosine-phosphate-guanine) dinucleotides. Hypermethylation of $\mathrm{CpG}$-rich sequences in gene promoter regions (called CpG islands) is usually associated with gene silencing, while hypomethylation is generally associated with gene expression (Jones 2012). DNA methylation is particularly important for reproduction due to its role in germ line reprogramming, occurring early in testis development, which involves the erasure and re-establishment of DNA methylation patterns in germ cells (Carrell 2012). After fertilization, the embryo undergoes a wave of genome-wide demethylation affecting the entire genome with the exception of imprinted genes and transposable repetitive elements (Hajkova et al. 2002). Imprinted genes refer to a group of biallelic genes expressed in a monoallelic, parent-of-origin-dependent manner. Paternally imprinted/methylated genes (e.g. H19) are usually highly 
methylated in sperm and unmethylated in oocytes, and are therefore expressed through the maternally inherited allele in the offspring (Masahiro 2011). In contrast, maternally imprinted/methylated genes (e.g. MEST) are usually methylated in the oocyte and unmethylated in sperm, being expressed through the paternally inherited copy throughout life (Masahiro 2011). Because of this lifelong maintenance of imprinting patterns in somatic lineages, defects in the methylation patterns in these regions have the potential to be transmitted to the offspring. The biallelic activation or inactivation of an imprinted gene could lead to imprinting disorders (e.g. Beckwith-Wiedemann [MIM130650] and PraderWilli [MIM176270] syndromes; Masahiro 2011). This abnormal activation or inactivation of imprinted genes might be the result of chromosomal deletion or duplication, uniparental disomy, gene mutations or imprinting defects related to abnormal DNA methylation (Horsthemke 2014). After implantation, a second wave of genome-wide demethylation takes place in primordial germ cells (PGCs), and erases the epigenetic marks of regions that had escaped the first wave of demethylation, in preparation for the establishment of the specific DNA methylation pattern for each parental germ line (Carrell 2012, Kobayashi et al. 2013, Tang et al. 2015). In the male germ line, this process is believed to occur after embryo implantation, following the migration of PGCs to the gonadal ridge (Kobayashi et al. 2013, Tang et al. 2015). Afterwards, the correct methylation patterns specific to the male germ line are re-established by de novo methylation (Davis et al. 2000, Obata \& Kono 2002, Saitou et al. 2012). This process, in mice, occurs a few days after erasure, whereas in humans, male PGCs appear to remain in an erased state for several weeks before re-methylation (Wermann et al. 2010, Kobayashi et al. 2013, Tang et al. 2015). In the case of imprinted genes, reprogramming causes both parental copies of paternally methylated genes to be fully re-methylated, while maternally methylated genes will remain unmethylated in the male germ line (Masahiro 2011). In addition to imprinted genes, data on human PGCs have shown that other genes have the ability to escape both waves of demethylation (Tang et al. 2015). These "escapee" genes include not only repetitive regions in the genome (such as LINEs) but also genes frequently expressed in the brain and neural development, as well as genes associated with obesity, cancer, bowel diseases and brain function (Tang et al. 2015). In theory, epimutations in these "escapee" genes would not be repaired and could constitute a potential mechanism for trans-generational epigenetic inheritance. This phenomenon has been suggested by several studies, but its magnitude is still under debate (Kläver et al. 2015, Wei et al. 2015). By acting on genes that retain their gametespecific DNA methylation patterns throughout life, the process of germ line reprogramming has potential consequences not only for spermatogenesis and sperm function but also for the offspring. Therefore, it must be kept in mind that factors disturbing this epigenetic mechanism in sperm might directly affect reproductive outcome.

\section{Sperm DNA methylation, infertility and ART outcome}

The strong association between aberrant DNA methylation of imprinted genes and abnormal sperm parameters, particularly sperm number, motility and morphology, has been extensively described in the literature and is summarized in Supplementary Table 1. In fact, a metaanalysis has shown that infertile men are more likely to have aberrant MEST $(\mathrm{OR}=3.4)$ or H19 $(\mathrm{OR}=14.62)$ methylation in sperm DNA when compared with fertile men (Kläver \& Gromoll 2014). These high ORs demonstrate a strong association between epimutations in MEST and H19 with male infertility. In addition to imprinted genes, DNA methylation levels of repetitive elements, e.g. LINES and ALU, and spermatogenesisrelevant genes (e.g. RHOX genes) have also been found to be altered in abnormal sperm (El Hajj et al. 2011, Richardson et al. 2013, Urdinguio et al. 2015).

Besides aberrant sperm parameters, abnormal DNA methylation in sperm has also been associated with the outcome of ART, including higher miscarriage rates (Supplementary Table 1). Furthermore, several authors have described an increased prevalence of imprinting disorders in ART offspring, although this link has never been successfully proven (DeBaun et al. 2003, Gicquel et al. 2003, Chang et al. 2005, Sutcliffe et al. 2006, Kobayashi et al. 2009, Zheng et al. 2011, Hiura et al. 2012, 2014, Cocchi et al. 2013). A meta-analysis has nevertheless found an increased OR for the prevalence of imprinted disorders in children born after ART compared with those born after spontaneous conception (Lazaraviciute et al. 2014). In addition, Kobayashi et al. (2009) showed that DNA methylation aberrations found in offspring could also, in a high proportion of the cases, be detected in the semen of the father, indicating an inherited epigenetic defect rather than an impact of ART procedures as an underlying cause for the epimutations. The use of sperm with aberrant DNA methylation (especially in imprinted genes that do not undergo reprogramming in somatic lineages and other genes that are able to escape both waves of epigenetic reprogramming) for ART and in particular ICSI might therefore bypass natural selection mechanisms and could result in severe consequences for the progeny that need to be carefully evaluated.

Although published data convincingly demonstrate that epimutations in sperm are associated with deleterious effects on fertility and reproductive outcome, the origin of sperm epimutations has only begun to be addressed. This lack of knowledge is mainly due to technical limitations rendering single-cell analysis difficult to perform. Therefore, it was not clear whether 
aberrant methylation levels were caused by an overall epigenetic defect affecting most sperm or by heterogeneity resulting in the presence of different sperm populations presenting with different epigenetic patterns within a single ejaculate.

\section{Epigenetic heterogeneity}

Advances in single-cell technologies have shown that even seemingly homogeneous populations show differences in gene expression, which might be directly linked to epigenetic heterogeneity (i.e. presence of mixed epigenetic patterns in a cell population or tissue; Lee et al. 2014). The idea of epigenetic heterogeneity originates from Waddington's concept of an epigenetic landscape in which epigenetic differences in a cell population lead to different lineages (Waddington 1939, Hemberger et al. 2009). The simplest form of epigenetic heterogeneity may result from the existence of a mixture of cell populations within a tissue, organ or cell line. A typical example of this is the difference in epigenetic status of white blood cell fractions. These differences have been suggested to be responsible for confounding methylation measurements in whole blood DNA due to the distinct amounts of specific cell types composing the blood of each individual (Adalsteinsson et al. 2012, Jaffe \& Irizarry 2014). Other examples are immortalized cell lines (e.g. HEK293), which usually serve as an essential research tool in everyday laboratory practice due to their perceived uniformity. The epigenetic heterogeneity found when comparing many commonly used cell lines obtained from different labs might explain why they may respond differently to similar stimuli and culture conditions (Putnik et al. 2015). Epigenetic heterogeneity might also reflect the plasticity of a cell or tissue. For instance, embryonic stem cells (ESCs) have been described to undergo a brief phase of epigenetic priming in which high levels of both DNA-methyltransferases (DNMTs; enzymes responsible for DNA methylation and its maintenance) and 10-11 translocation enzymes (TET; enzymes that have been shown to be involved in DNA demethylation) are expressed (Seisenberger et al. 2012, Ficz et al. 2013). This overexpression/overactivity of both enzyme types results not only in epigenetic but also in transcriptional heterogeneity, which ultimately enables the individual cells to respond differently to the various stimuli (Lee et al. 2014). This, in turn, contributes to cell fate decisions that lead to the commitment into different cell lineages (Lee et al. 2014). In line with the Waddington concept, it has been shown that the potential of somatic cells to be reprogrammed into induced pluripotent stem (iPS) cells can be increased by disturbing their epigenetic state with treatments affecting histone modifications and creating epigenetic heterogeneity before factor induction (Pour et al. 2015). Cancer is another pivotal example of epigenetic heterogeneity, a factor that contributes to tumour cell plasticity, and might therefore be the major underlying cause for poor prognosis and survival rates for several cancers, including prostate cancer (De et al. 2013, Brocks et al. 2014, Shaknovich et al. 2014).

\section{Sperm epigenetic heterogeneity}

Until recently, data on the putative epigenetic heterogeneity of human sperm were scarce. The first report focusing on intra-individual epigenetic variation in human sperm used normozoospermic sperm donors and identified a small degree of heterogeneity in several diseaserelated genes, including BRCA1 and BRCA2 (Flanagan et al. 2006). Following this, Krausz et al. (2012) described how different-quality fractions obtained by discontinuous gradient from the sperm of a single individual do not vary significantly in their DNA methylation profiles.

Most studies dealing with methylation defects in the sperm of infertile men used large semen samples and were not able to account for possible cell heterogeneity due to the technical limitations of methods being applied. The most widely used method, bisulphite sequencing (involving bisulphite treatment, cloning of PCR products and sequencing), is restricted to the limited number of clones that can be analysed from each given sample. As a consequence, the usefulness of this method in evaluating epigenetic heterogeneity and mosaicism is limited. Nevertheless, when carefully re-analysing the methylation patterns obtained from previous studies that used cloning and sequencing for the analysis of DNA methylation in sperm, it becomes clear that some data already indicated the presence of epigenetic heterogeneity/mosaicism in sperm. The patterns shown by several of the clones sequenced (Flanagan et al. 2006, Kobayashi et al. 2007, Marques et al. 2008, Hammoud et al. 2010, Marques et al. 2010, Wu et al. 2010, Minor et al. 2011, Sato et al. 2011, Ankolkar et al. 2012, Montjean et al. 2013) resemble at a small scale the binomial (sequences fully methylated vs fully unmethylated) distribution of sequencing patterns obtained using deep-bisulphite sequencing (DBS; Laurentino et al. 2015). Due to the requirement for a high number of individual sequences analysed from each single sample, the detection and measurement of epigenetic heterogeneity in sperm as well as in other tissues only became feasible now, with the advent of high-resolution analysis methodologies such as nextgeneration sequencing/DBS (Mikeska et al. 2010, Meaburn \& Schulz 2012, Beygo et al. 2013, Gries et al. 2013, Smallwood et al. 2014, Putnik et al. 2015). The use of novel and highly sensitive DNA isolation and pyrosequencing-based sequencing techniques, such as OSMA (oligo-sperm methylation assay; Laurentino et al. 2015) and limiting dilution (LD; Kuhtz et al. 2014), allowed the detection of DNA methylation heterogeneity in the sperm of infertile men. This heterogeneity could be further confirmed using DBS, which enabled 
the undoubted detection of epigenetically distinct sperm populations in the semen of a group of infertile men (Fig. 1). These results strongly support the concept that aberrant DNA methylation at imprinted genes is due to the occurrence of epigenetic mosaicism in semen. Additional analyses using a specific H19 SNP within the analysed region lead to separation of both parental alleles revealing that epimutations occurred preferentially at the maternally inherited allele and retained an oocyte-like imprinting pattern. This finding suggests that a failure in the reprogramming in some of the PGCs or gonocytes early in development might be responsible for the occurrence of sperm epimutations. A defect in the epigenetic reprogramming of PGCs, specifically defective erasure of DNA methylation marks, as the origin for the aberrant levels of DNA methylation in infertile men has been previously suggested, due to the preferential detection of hypermethylation-affecting genes normally unmethylated in the sperm of infertile males (Houshdaran et al. 2007).

It is noteworthy that a high and constant fraction of epimutated sperm cells could be repeatedly detected for all analysed genes in each sample from a cohort of infertile men presenting with oligoasthenoteratozoospermic and abnormal average MEST DNA methylation (Laurentino et al. 2015). This pattern is reminiscent, and in accordance with, the spermatogenic system present in human testes, in which a large number of progenitor cells (type A pale spermatogonia), originating from the same original small pool of PGCs, give rise to a relatively small number of sperm ( 16 from each cell that enters differentiation; Ehmcke \& Schlatt 2006, Ehmcke et al. 2006). This creates a chance for the propagation of distinct DNA methylation patterns through the successive cell divisions, with the earlier the occurrence of the original epimutation, the higher the number of SSCs and therefore sperm ultimately affected in the ejaculate.

The idea that male infertility and affected germ cells might be more prone to epigenetic heterogeneity has been corroborated by Jenkins et al. (2014), who separated sperm from normozoospermic men into "high-quality" and "low-quality" quality fractions by discontinuous gradient and analysed the respective DNA methylation patterns. Several differentially methylated regions were identified between the fractions, sug- gesting that some loci are more susceptible to variation than others. However, these variations did not seem to equally affect all the sperm in the "low-quality" fraction (Jenkins et al. 2014). This further indicates that a single ejaculate might contain subpopulations of sperm with different methylation patterns, probably resulting from alterations in a portion of the spermatogonial cell population. This notion was corroborated by Kuhtz et al. (2014), wherein the DNA methylation of several genes was evaluated by LD and DBS. A higher rate of epimutations was detected in sperm from OAT men compared with fertile controls. However, by DBS, only a few of the OAT patients analysed (none of which had resulted in pregnancy) showed a high percentage of abnormal alleles, indicative for a severe methylation defect. This seeming difference in the severity of epimutations found using the same DBS system (Roche 454/GS Junior; Kuhtz et al. 2014, Laurentino et al. 2015) is only apparent and can be explained by the different criteria used for sample selection (pre-screening for DNA methylation defects vs fertilization ability).

Currently, the temporal and cellular origin of epimutations and epigenetic heterogeneity is unknown and can only be determined by analysing specific germ cell types at different stages of development. However, the pattern of epimutations found in men with epigenetic mosaicism seems to point towards a clonal expansion of the originally affected cells. This suggests that abnormal DNA methylation in sperm originates during prenatal life, early in development, and could be caused by an incomplete reprogramming of the male germ line (Laurentino et al. 2015). This scenario does not exclude the possibility that the epigenetic programming of the germ line might be affected during later stages of development (pre- and post-pubertal) and by external factors, although the effects would be of a different magnitude. For instance, it has been reported that obesity has an impact on the epigenetic pattern of sperm and that subsequent weight loss induces changes in sperm DNA methylation in genomic regions associated with the control of appetite (Donkin et al. 2015). Although the causes for the co-existence of multiple, differentially methylated populations of sperm are, so far, unknown, it is to be assumed that an epigenetic mosaicism can be caused by both extrinsic and intrinsic factors, such as genotype, hormones and the environment (Fig. 2).
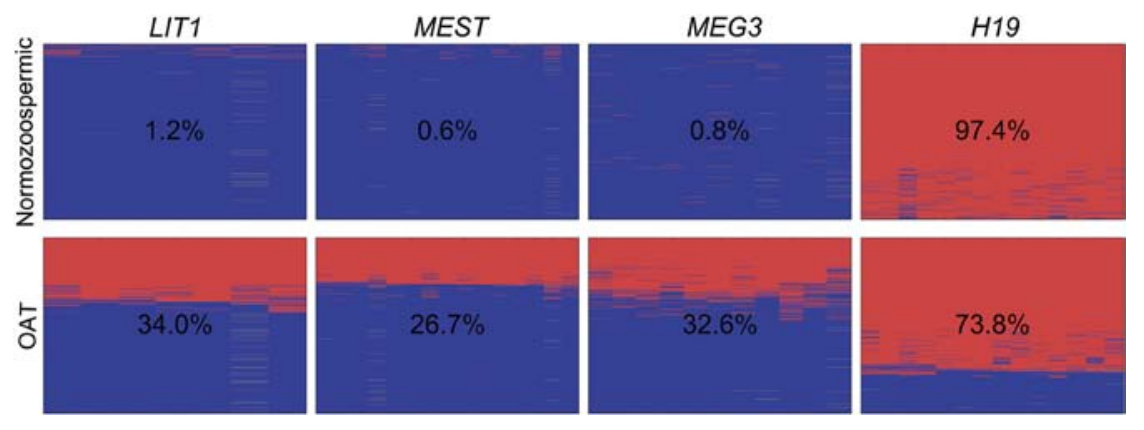

Figure 1 Results for deep bisulphite sequencing of imprinted genes KCNQ1OT1/ LIT1, MEST, MEG3 and H19 in men with normozoospermic (upper panel) and oligoasthenoteratozoospermic (lower panel) sperm parameters. Each vertical position represents one $\mathrm{CpG}$ site, and every horizontal line represents a unique sequence read. A red line denotes that the site was methylated and a blue line denotes that it was unmethylated (adapted from Laurentino et al. 2015). 
Genetic variations, for example, in genes encoding enzymes important for DNA methylation and demethylation pathways, are known to affect the process of imprint establishment itself. Mice deficient in Tet 1 and Tet2 have been shown to have abnormal methylation at imprinted genes (Dawlaty et al. 2013, Bermejo-Alvarez et al. 2015). Reproductive hormones might also affect proper DNA methylation during testis development, an influence that has been demonstrated by the direct effect of sex steroid hormones on brain development, a process that is mediated by regulation of DNA methylation (Nugent et al. 2015). Moreover, it is possible that the germ cell niche, which plays an important role in the determination of SSC fate (Chen et al. 2014, Chen \& Liu 2015), also contributes to the maintenance and regulation of the epigenetic state of germ cells (OliverosEtter et al. 2015). The removal of PGCs from the niche leads to their reversion to embryonic germ cell state, along with disturbance of the specific germ line imprints (Oliveros-Etter et al. 2015). In addition to the aforementioned factors (Donkin et al. 2015, Pacchierotti \& Spanò 2015), other environmental influences such as endocrine disruptors (e.g. vincozolin and bisphenol A) have been described as having an impact specifically on the epigenetic programming of the male germ line and causing epimutations in sperm (Manikkam et al. 2013, Iqbal et al. 2015). Finally, ageing is able to change the SSC composition of testis and might also alter the proportion of aberrantly methylated sperm found in an ejaculate (Paul \& Robaire 2013; Fig. 2).

Based on the available data and concepts on epigenetic heterogeneity, we propose a model addressing the possible origin of epimutations and epigenetic heterogeneity in sperm (Fig. 2). According to this, the different factors could potentially affect the germ line at epigenetically sensitive periods (e.g. during germ line reprogramming or during later life) to disturb the methylation patterns of spermatogenic cells. These changes, if not directly impairing spermatogenesis, will not be 'repaired' and could persist throughout spermatogenesis and be forwarded to the progeny (Fig. 2). The fact that the epigenetically aberrant sperm populations were preferentially found in men with severe sperm abnormalities and that non-imprinted genes are also affected (Supplementary Table 1) suggests that there might be a link between phenotype and epigenotype.

It is important to note that there are clear evidences that spermatogonia might also have a degree of constitutive heterogeneity at the gene expression and epigenetic level, at least in mouse models, that allows the cells to retain a certain degree of plasticity (Hammoud et al. 2015, Hermann et al. 2015). This is in accordance with data from other cell types indicating that epigenetic heterogeneity is usually connected to transcriptional heterogeneity. This is, presumably, a mechanism that enables spermatogonia to react to stimuli and interact with the stem cell niche differently and might be linked to decision-making pathways in these cells, i.e. either to replenish the testicular stem cell pool or to progress through spermatogenesis (Hammoud et al. 2015, Hermann et al. 2015, Krieger \& Simons 2015). Whether such constitutive spermatogonial heterogeneity is also present in humans (and if this mechanism is perturbed in infertile patients) remains to be explored.

\section{Conclusions and future perspectives}

Taken together, the available literature indicates a clear association between abnormal DNA methylation patterns in sperm and male infertility. However, this adverse outcome might not be due to a broad epigenetic defect affecting the gametes of these men.

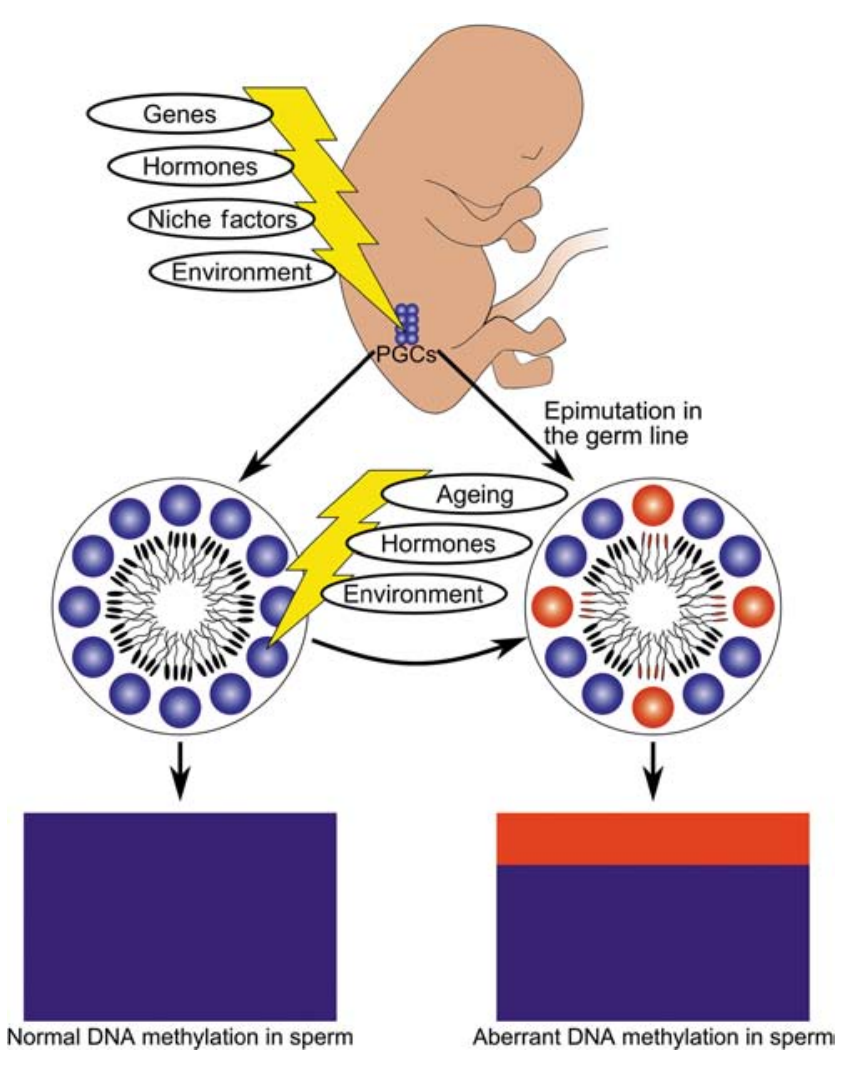

Figure 2 Model for the occurrence of epigenetic heterogeneity in human sperm. Multiple stimuli including genetic background (e.g. variations and mutations in genes encoding TET and DNMT enzymes), steroid hormones, factors secreted by the stem cell niche and the environment might affect the primordial germ cells (PGCs) at phases of epigenetic vulnerability such as during reprogramming. This results in different populations of spermatogonia and ultimately, in adulthood, in sperm with different epigenetic statuses. The extent of aberrant reads, measured by deep bisulphite sequencing (lower pane/s), will be proportional to the number of spermatogonia and sperm affected by the epimutations. Moreover, throughout life, these same stimuli and also the process of ageing itself can also affect the epigenetic programming or alter the population of resident spermatogonial stem cells. This might further induce the occurrence of epimutations or might change the proportion of sperm presenting with aberrant DNA methylation patterns in the ejaculate. 
Instead, it is more probably caused by the production of a portion of sperm that has aberrant DNA methylation levels along with a population that presents normal epigenetic programming. The selection of this high (epi)quality sperm fraction is currently impossible due to the inexistence of methods that allow the measurement of DNA methylation levels without leading to the destruction of the analysed cells. The development of such a technique could have a major impact not only on the outcome of ART but also to its safety. However, the development of therapeutical options for men with germ line epimutations could also have a similar impact to the field of reproductive medicine. Although intrinsic factors, such as alterations in genes involved in epigenetic regulation, might not be corrigible, other possible culprits, such as hormones or environmental factors, might be suitable targets for pharmacological treatments or even prevention strategies. However, in order to identify possible intervention approaches, the source and causes for the occurrence of epimutations and epigenetic heterogeneity in sperm must be specifically identified and should be considered as a priority in current reproductive research.

\section{Supplementary data}

This is linked to the online version of the paper at http://dx.doi. org/10.1530/REP-15-0436.

\section{Declaration of interest}

The authors declare that there is no conflict of interest that could be perceived as prejudicing the impartiality of the research reported.

\section{Funding}

This work was financed by the Deutsche Forschungsgemeinschaft (DFG FOR1041/2 and GR1547/19-1) and the Innovative Medizinische Forschung an der Medizinischen Fakultät Münster (LA121315).

\section{References}

Adalsteinsson BT, Gudnason H, Aspelund T, Harris TB, Launer LJ, Eiriksdottir G, Smith AV \& Gudnason V 2012 Heterogeneity in white blood cells has potential to confound DNA methylation measurements. PloS One 7 e46705. (doi:10.1371/journal.pone.0046705)

Ankolkar M, Patil A, Warke H, Salvi V, KediaMokashi N, Pathak S \& Balasinor NH 2012 Methylation analysis of idiopathic recurrent spontaneous miscarriage cases reveals aberrant imprinting at H19 ICR in normozoospermic individuals. Fertility and Sterility 98 1186-1192. (doi:10.1016/j.fertnstert.2012.07.1143)

Berger SL, Kouzarides T, Shiekhattar R \& Shilatifard A 2009 An operational definition of epigenetics. Genes \& Development 23 781-783. (doi:10.15252/embr.201439264)

Bermejo-Alvarez P, Ramos-Ibeas P, Park KE, Powell AP, Vansandt L, Derek B, Ramirez MA, Gutierrez-Adan A \& Telugu BP 2015 Tet-mediated imprinting erasure in H19 locus following reprogramming of spermatogonial stem cells to induced pluripotent stem cells. Scientific Reports 5 13691. (doi:10.1016/j.gene.2015.01.063)

Beygo J, Ammerpohl O, Gritzan D, Heitmann M, Rademacher K, Richter J, Caliebe A, Siebert R, Horsthemke B \& Buiting K 2013 Deep bisulfite sequencing of aberrantly methylated Loci in a patient with multiple methylation defects. PloS One 8 e76953. (doi:10.1371/journal.pone. 0076953)

Brocks D, Assenov Y, Minner S, Bogatyrova O, Simon R, Koop C, Oakes C, Zucknick M, Lipka DB, Weischenfeldt J, Feuerbach L, Cowper-Sal Lari R, Lupien M, Brors B, Korbel J, Schlomm T, Tanay A, Sauter G, Gerhauser C Plass C \& ICGC Early Onset Prostate Cancer Project 2014 Intratumor DNA methylation heterogeneity reflects clonal evolution in aggressive prostate cancer. Cell Reports 8 798-806. (doi:10.1016/j. celrep.2014.06.053)

Carrell DT 2012 Epigenetics of the male gamete. Fertility and Sterility 97 267-274.

Chang AS, Moley KH, Wangler M, Feinberg AP \& Debaun MR 2005 Association between Beckwith-Wiedemann syndrome and assisted reproductive technology: a case series of 19 patients. Fertility and Sterility 83 349-354.

Chen SR \& Liu YX 2015 Regulation of spermatogonial stem cell self-renewal and spermatocyte meiosis by Sertoli cell signaling. Reproduction 149 R159-R167. (doi:10.1530/REP-14-0481)

Chen LY, Brown PR, Willis WB \& Eddy EM 2014 Peritubularmyoid cells participate in male mouse spermatogonial stem cell maintenance. Endocrinology 155 4964-4974. (doi:10.1210/en.2014-1406)

Cocchi G, Marsico C, Cosentino A, Spadoni C, Rocca A, De Crescenzo A \& Riccio A 2013 Silver-Russell syndrome due to paternal H19/IGF2 hypomethylation in a twin girl born after in vitro fertilization. American Journal of Medical Genetics. Part A 161A 2652-2655. (doi:10.1002/ ajmg.a.36145)

Davis TL, Yang GJ, McCarrey JR \& Bartolomei MS 2000 The H19 methylation imprint is erased and re-established differentially on the parental alleles during male germ cell development. Human Molecular Genetics 9 2885-2894.

Dawlaty MM, Breiling A, Le T, Raddatz G, Barrasa MI, Cheng AW, Gao Q, Powell BE, Li Z, Xu M, Faull KF, Lyko F \& Jaenisch R 2013 Combined deficiency of Tet1 and Tet2 causes epigenetic abnormalities but is compatible with postnatal development. Developmental Cell 24 310-323. (doi:10.1016/j.devcel.2012.12.015)

De S, Shaknovich $R$, Riester $M$, Elemento $O$, Geng $H$, Kormaksson $M$, Jiang Y, Woolcock B, Johnson N, Polo JM, Cerchietti L, Gascoyne RD, Melnick A \& Michor F 2013 Aberration in DNA methylation in B-cell lymphomas has a complex origin and increases with disease severity. PLoS Genetics 9 e1003137. (doi:10.1371/journal.pgen.1003137)

DeBaun MR, Niemitz EL \& Feinberg AP 2003 Association of in vitro fertilization with Beckwith-Wiedemann syndrome and epigenetic alterations of LIT1 and H19. American Journal of Human Genetics 72 156-160.

Donkin I, Versteyhe S, Ingerslev LR, Qian K, Mechta M, Nordkap L, Mortensen B, Appel EV, Jorgensen N, Kristiansen VB et al. 2015 Obesity and Bariatric Surgery Drive Epigenetic Variation of Spermatozoa in Humans. Cell Metabolism 23 369-378. (doi:10.1016/j. cmet.2015.11.004)

Ehmcke J \& Schlatt S 2006 A revised model for spermatogonial expansion in man: lessons from non-human primates. Reproduction 673-680.

Ehmcke J, Wistuba J \& Schlatt S 2006 Spermatogonial stem cells: questions, models and perspectives. Human Reproduction Update 12 275-282.

El Hajj N, Zechner U, Schneider E, Tresch A, Gromoll J, Hahn T, Schorsch M \& Haaf T 2011 Methylation status of imprinted genes and repetitive elements in sperm DNA from infertile males. Sexual Development: Genetics, Molecular Biology, Evolution, Endocrinology, Embryology, and Pathology of Sex Determination and Differentiation 5 60-69. (doi:10.1159/000323806)

Ficz G, Hore TA, Santos F, Lee HJ, Dean W, Arand J, Krueger F, Oxley D, Paul YL, Walter J et al. 2013 FGF signaling inhibition in ESCs drives rapid genome-wide demethylation to the epigenetic ground state of pluripotency. Cell Stem Cell 13 351-359. (doi:10.1016/j. stem.2013.06.004)

Flanagan JM, Popendikyte V, Pozdniakovaite N, Sobolev M, Assadzadeh A, Schumacher A, Zangeneh M, Lau L, Virtanen C, Wang SC et al. 2006 
Intra- and interindividual epigenetic variation in human germ cells. American Journal of Human Genetics 79 67-84.

Gicquel C, Gaston V, Mandelbaum J, Siffroi JP, Flahault A \& Le Bouc Y 2003 In vitro fertilization may increase the risk of Beckwith-Wiedemann syndrome related to the abnormal imprinting of the KCN1OT gene. American Journal of Human Genetics 72 1338-1341.

Gries J, Schumacher D Arand J, Lutsik P, Markelova MR, Fichtner I, Walter J, Sers C \& Tierling S 2013 Bi-PROF: bisulfite profiling of target regions using 454 GS FLX Titanium technology. Epigenetics 8 765-771. (doi:10.4161/epi.25242)

Hajkova P, Erhardt S, Lane N, Haaf T, El-Maarri O, Reik W, Walter J \& Surani MA 2002 Epigenetic reprogramming in mouse primordial germ cells. Mechanisms of Development 117 15-23.

Hammoud SS, Purwar J, Pflueger C, Cairns BR \& Carrell DT 2010 Alterations in sperm DNA methylation patterns at imprinted loci in two classes of infertility. Fertility and Sterility 94 1728-1733. (doi:10.1016/j. fertnstert.2009.09.010)

Hammoud SS, Low DH, Yi C, Lee CL, Oatley JM, Payne CJ, Carrell DT, Guccione E \& Cairns BR 2015 Transcription and imprinting dynamics in developing postnatal male germ line stem cells. Genes \& Development 29 2312-2324. (doi:10.1101/gad.261925.115)

Hemberger M, Dean W \& Reik W 2009 Epigenetic dynamics of stem cells and cell lineage commitment: digging Waddington's canal. Nature Reviews Molecular Cell Biology 10 526-537. (doi:10.1038/nrm2727)

Hermann BP, Mutoji KN, Velte EK, Ko D, Oatley JM, Geyer CB \& McCarrey JR 2015 Transcriptional and translational heterogeneity among neonatal mouse spermatogonia. Biology of Reproduction 9254. (doi:10.1095/biolreprod.114.125757)

Hiura H, Okae H, Miyauchi N, Sato F, Sato A, Van De Pette M, John RM, Kagami M, Nakai K, Soejima H et al. 2012 Characterization of DNA methylation errors in patients with imprinting disorders conceived by assisted reproduction technologies. Human Reproduction 27 2541-2548. (doi:10.1093/humrep/des197)

Hiura H, Okae H, Chiba H, Miyauchi N, Sato F, Sato A \& Arima T 2014 Imprinting methylation errors in ART. Reproductive Medicine and Biology 13 193-202.

Horsthemke B 2014 In brief: genomic imprinting and imprinting diseases. Journal of Pathology 232 485-487. (doi:10.1002/path.4326)

Houshdaran S, Cortessis VK, Siegmund K, Yang A, Laird PW \& Sokol RZ 2007 Widespread epigenetic abnormalities suggest a broad DNA methylation erasure defect in abnormal human sperm. PloS One 2 e1289.

Iqbal K, Tran DA, Li AX, Warden C, Bai AY, Singh P, Wu X, Pfeifer GP \& Szabo PE 2015 Deleterious effects of endocrine disruptors are corrected in the mammalian germ line by epigenome reprogramming. Genome Biology 16 59. (doi:10.1186/s13059-015-0619-z)

Jaffe AE \& Irizarry RA 2014 Accounting for cellular heterogeneity is critical in epigenome-wide association studies. Genome Biology 15 R31. (doi:10.1186/gb-2014-15-2-r31)

Jenkins TG, Aston KI, Trost C, Farley J, Hotaling JM \& Carrell DT 2014 Intra-sample heterogeneity of sperm DNA methylation. Molecular Human Reproduction 21 313-319. (doi:10.1093/molehr/gau115)

Jones PA 2012 Functions of DNA methylation: islands, start sites, gene bodies and beyond. Nature Reviews Genetics 13 484-492. (doi:10.1038/ nrg3230)

Kläver R \& Gromoll J 2014 Bringing epigenetics into the diagnostics of the andrology laboratory: challenges and perspectives. Asian Journal of Andrology 16 669-674. (doi:10.4103/1008-682X.125412)

Kläver R, Sanchez V, Damm OS, Redmann K, Lahrmann E, SandhoweKlaverkamp R, Rohde C, Wistuba J, Ehmcke J, Schlatt S et al. 2015 Direct but no transgenerational effects of decitabine and vorinostat on male fertility. PloS One 10 e0117839. (doi:10.1371/journal.pone.0117839)

Kobayashi H, Sato A, Otsu E, Hiura H, Tomatsu C, Utsunomiya T, Sasaki H, Yaegashi N \& Arima T 2007 Aberrant DNA methylation of imprinted loci in sperm from oligospermic patients. Human Molecular Genetics 16 2542-2551.

Kobayashi H, Hiura H, John RM, Sato A, Otsu E, Kobayashi N, Suzuki R, Suzuki F, Hayashi C, Utsunomiya T et al. 2009 DNA methylation errors at imprinted loci after assisted conception originate in the parental sperm. European Journal of Human Genetics 17 1582-1591. (doi:10.1038/ ejhg.2009.68)

Kobayashi H, Sakurai T, Miura F, Imai M, Mochiduki K, Yanagisawa E, Sakashita A, Wakai T, Suzuki Y, Ito T et al. 2013 High-resolution DNA methylome analysis of primordial germ cells identifies gender-specific reprogramming in mice. Genome Research 23 616-627. (doi:10.1101/ gr.148023.112)

Krausz C, Sandoval J, Sayols S, Chianese C, Giachini C, Heyn H \& Esteller M 2012 Novel insights into DNA methylation features in spermatozoa: stability and peculiarities. PloS One 7 e44479. (doi:10.1371/journal. pone.0044479)

Krieger T \& Simons BD 2015 Dynamic stem cell heterogeneity. Development 142 1396-1406.

Kuhtz J, Schneider E, El Hajj N, Zimmermann L, Fust O, Linek B, Seufert R, Hahn T, Schorsch M \& Haaf T 2014 Epigenetic heterogeneity of developmentally important genes in human sperm: implications for assisted reproduction outcome. Epigenetics 9 1648-1658. (doi:10.416 1/15592294.2014.988063)

Laurentino S, Beygo J, Nordhoff V, Kliesch S, Wistuba J, Borgmann J, Buiting K, Horsthemke B \& Gromoll J 2015 Epigenetic germlinemosaicism in infertile men. Human Molecular Genetics 24 1295-1304. (doi:10.1093/hmg/ddu540)

Lazaraviciute G, Kauser M, Bhattacharya S, Haggarty P \& Bhattacharya S 2014 A systematic review and meta-analysis of DNA methylation levels and imprinting disorders in children conceived by IVF/ICSI compared with children conceived spontaneously. Human Reproduction Update 20 840-852. (doi:10.1093/humupd/dmu033)

Lee HJ, Hore TA \& Reik W 2014 Reprogramming the methylome: erasing memory and creating diversity. Cell Stem Cell 14 710-719. (doi:10.1016/j.stem.2014.05.008)

Manikkam M, Tracey R, Guerrero-Bosagna C \& Skinner MK 2013 Plastics derived endocrine disruptors (BPA, DEHP and DBP) induce epigenetic transgenerational inheritance of obesity, reproductive disease and sperm epimutations. PloS One 8 e55387. (doi:10.1371/journal.pone.0055387)

Marque CJ, Costa P, Vaz B, Carvalho F, Fernandes S, Barros A \& Sousa M 2008 Abnormal methylation of imprinted genes in human sperm is associated with oligozoospermia. Molecular Human Reproduction 14 67-74.

Marques CJ, Francisco T, Sousa S, Carvalho F, Barros A \& Sousa M 2010 Methylation defects of imprinted genes in human testicular spermatozoa. Fertility and Sterility 94 585-594. (doi:10.1016/j. fertnstert.2009.02.051)

Masahiro K 2011 Genomic imprinting in mammals - epigenetic parental memories. Differentiation 82 51-56. (doi:10.1016/j.diff.2011.05.004)

Meaburn E \& Schulz R 2012 Next generation sequencing in epigenetics: insights and challenges. Seminars in Cell \& Developmental Biology 23 192-199. (doi:10.1016/j.semcdb.2011.10.010)

Mikeska T Candiloro IL \& Dobrovic A 2010 The implications of heterogeneous DNA methylation for the accurate quantification of methylation. Epigenomics 2 561-573. (doi:10.2217/epi.10.32)

Minor A, Chow V \& Ma S 2011 Aberrant DNA methylation at imprinted genes in testicular sperm retrieved from men with obstructive azoospermia and undergoing vasectomy reversal. Reproduction $\mathbf{1 4 1}$ 749-757. (doi:10.1530/REP-11-0008)

Montjean D, Ravel C, Benkhalifa M, Cohen-Bacrie P, Berthaut I, Bashamboo A \& McElreavey K 2013 Methylation changes in mature sperm deoxyribonucleic acid from oligozoospermic men: assessment of genetic variants and assisted reproductive technology outcome. Fertility and Sterility 100 1241-1247. (doi:10.1016/j.fertnstert.2013.06.047)

Nugent BM, Wright CL, Shetty AC, Hodes GE, Lenz KM, Mahurkar A, Russo SJ, Devine SE \& McCarthy MM 2015 Brain feminization requires active repression of masculinization via DNA methylation. Nature Neuroscience 18 690-697. (doi:10.1038/nn.3988)

Obata Y \& Kono T 2002 Maternal primary imprinting is established at a specific time for each gene throughout oocyte growth. Journal of Biological Chemistry 277 5285-5289.

Oliveros-Etter M, Li Z, Nee K, Hosohama L, Hargan-Calvopina J, Lee SA, Joti P, Yu J \& Clark AT 2015 PGC reversion to pluripotency involves erasure of DNA methylation from imprinting control centers followed by locus-specific re-methylation. Stem Cell Reports 5 337-349. (doi:10.1016/j.stemcr.2015.07.006)

Pacchierotti F \& Spano M 2015 Environmental Impact on DNA Methylation in the germ line: state of the art and gaps of knowledge. BioMed Research International 2015 123484. (doi:10.1155/2015/123484)

Paul C \& Robaire B 2013 Ageing of the male germ line. Nature Reviews Urology 10 227-234.

Pour M, Pilzer I, Rosner R, Smith ZD, Meissner A \& Nachman I 2015 Epigenetic predisposition to reprogramming fates in somatic cells. EMBO Reports 16 370-378. (doi:10.15252/embr.201439264) 
Putnik M, Wojdacz TK, Pournara A, Vahter M \& Wallberg AE 2015 MS-HRM assay identifies high levels of epigenetic heterogeneity in human immortalized cell lines. Gene 560 165-172. (doi:10.1016/j. gene.2015.01.063)

Richardson ME, Bleiziffer A, Tuttelmann F, Gromoll J \& Wilkinson MF 2013 Epigenetic regulation of the RHOX homeobox gene cluster and its association with human male infertility. Human Molecular Genetics 23 12-23. (doi:10.1093/hmg/ddt392)

Saitou M, Kagiwada S \& Kurimoto K 2012 Epigenetic reprogramming in mouse pre-implantation development and primordial germ cells. Development 139 15-31. (doi:10.1093/hmg/ddt392)

Sato A, Hiura H, Okae H, Miyauchi N, Abe Y, Utsunomiya T, Yaegashi N \& Arima T 2011 Assessing loss of imprint methylation in sperm from subfertile men using novel methylation polymerase chain reaction Luminex analysis. Fertility and Sterility 95 129-134, 134.e1-e4. (doi:10.1016/j.fertnstert.2010.06.076)

Seisenberger S, Andrews S, Krueger F, Arand J, Walter J, Santos F, Popp C, Thienpont B, Dean W \& Reik W 2012 The dynamics of genome-wide DNA methylation reprogramming in mouse primordial germ cells. Molecular Cell 48 849-862. (doi:10.1016/j. molcel.2012.11.001)

Shaknovich R, De S \& Michor F 2014 Epigenetic diversity in hematopoietic neoplasms. Biochimica et Biophysica Acta 1846 477-484. (doi:10.1016/j. bbcan.2014.09.003)

Smallwood SA, Lee HJ, Angermueller C, Krueger F, Saadeh H, Peat J, Andrews SR, Stegle O, Reik W \& Kelsey G 2014 Single-cell genomewide bisulfite sequencing for assessing epigenetic heterogeneity. Nature Methods 11 817-820. (doi:10.1038/nmeth.3035)

Sutcliffe AG, Peters CJ, Bowdin S, Temple K, Reardon W, Wilson L, Clayton-Smith J, Brueton LA, Bannister W \& Maher ER 2006 Assisted reproductive therapies and imprinting disorders - a preliminary British survey. Human Reproduction 21 1009-1011.

Tang WW, Dietmann S, Irie N, Leitch HG, Floros VI, Bradshaw CR, Hackett JA, Chinnery PF \& Surani MA 2015 A unique gene regulatory network resets the human germline epigenome for development. Cell 161 1453-1467. (doi:10.1016/j.cell.2015.04.053)

Tüttelmann F, Gromoll J \& Kliesch S 2008 Genetics of male infertility. Der Urologe. Ausg. A 47 1561-1562, 1564-1567.

Urdinguio RG Bayon GF, Dmitrijeva M, Torano EG, Bravo C, Fraga MF, Bassas L, Larriba S \& Fernandez AF 2015 Aberrant DNA methylation patterns of spermatozoa in men with unexplained infertility. Human Reproduction 30 1014-1028. (doi:10.1093/humrep/dev053)

Waddington CH 1939 An Introduction to Modern Genetics. New York: The Macmillan Company.

Wei Y, Schatten H \& Sun QY 2015 Environmental epigenetic inheritance through gametes and implications for human reproduction. Human Reproduction Update 21 194-208. (doi:10.1093/humupd/dmu061)

Wermann H, Stoop H, Gillis AJ, Honecker F, van Gurp RJ, Ammerpohl O, Richter J, Oosterhuis JW, Bokemeyer C \& Looijenga LH 2010 Global DNA methylation in fetal human germ cells and germ cell tumours: association with differentiation and cisplatin resistance. Journal of Pathology 221 433-442. (doi:10.1002/path.2725)

Wu W, Shen O, Qin Y, Niu X, Lu C, Xia Y, Song L, Wang S \& Wang X 2010 Idiopathic male infertility is strongly associated with aberrant promoter methylation of methylenetetrahydrofolate reductase (MTHFR). PloS One 5 e13884. (doi:10.1371/journal.pone.0013884)

Zheng HY, Shi XY, Wang LL, Wu YQ, Chen SL \& Zhang L 2011 Study of DNA methylation patterns of imprinted genes in children born after assisted reproductive technologies reveals no imprinting errors: a pilot study. Experimental and Therapeutic Medicine 2 751-755.

Received 15 September 2015

First decision 10 November 2015

Revised manuscript received 9 February 2016

Accepted 15 February 2016 